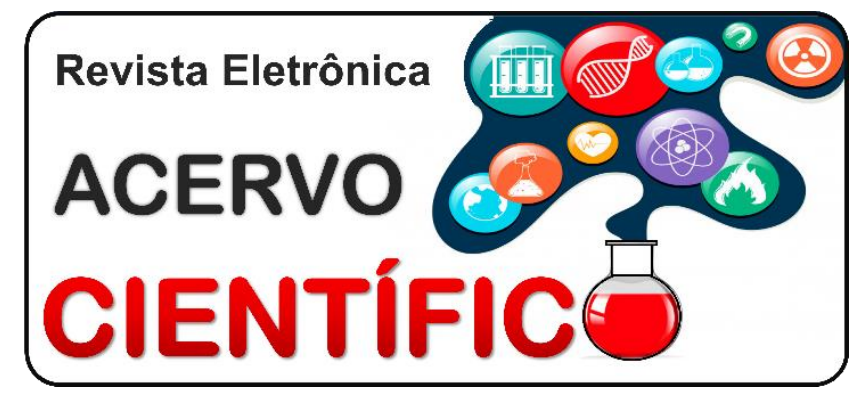

\section{ARTIGO ORIGINAL}

Recebido em: 10/2020

Aceito em: $11 / 2020$

Publicado em: 1/2021

\title{
Análise do cardápio fornecido aos discentes do ensino fundamental em um município do Amazonas
}

\author{
Analysis of the menu provided to elementary school students in a municipality in \\ Amazonas
}

Análisis del menú brindado a estudiantes de primaria en un municipio de Amazonas

Rainara de Souza Oliveira ${ }^{1 *}$, Aline Pereira Penha ${ }^{1}$, Raquel Peres de Oliveira ${ }^{1}$, Luziane Bastos de Oliveira1', Gustavo Bernardes Fanaro'1.

Resumo: Esta pesquisa teve o objetivo realizar a análise do cardápio escolar fornecido aos discentes do ensino fundamental das redes Municipal e Estadual de ensino de um município do interior do Amazonas, comparando os dados encontrados com as recomendações descritas no Programa Nacional de Alimentação Escolar (PNAE). Os dados foram obtidos através da coleta de informações dos cardápios, das fichas de preparações e das porções das refeições servidas no mês de outubro de 2019 nas escolas de ensino fundamental da rede Municipal e Estadual de ensino em um município do Amazonas. Durante a análise dos dados foi encontrado uma grande prevalência de inadequações na composição nutricional do cardápio ofertado aos escolares tanto na quantidade de energia, quanto nas quantidades de macro e micronutrientes. As inadequações dos valores encontrados na composição nutricional do cardápio escolar são prejudiciais e expõem os alunos as carências nutricionais, além de influenciar no desenvolvimento físico, intelectual e mental dos estudantes.

Palavras-chave: Alimentação escolar, Planejamento de cardápio, Deficiências nutricionais.

\begin{abstract}
This research aimed to carry out the analysis of the school menu provided to students of elementary education in the Municipal and State networks of a municipality in the interior of Amazonas, comparing the data found with the recommendations described in the National School Feeding Program (PNAE). The data were obtained through the collection of information from the menus, the preparation sheets and the portions of the meals served in October 2019 in the elementary schools of the Municipal and State network of education in a municipality in Amazonas. During the analysis of the data it was found a great prevalence of inadequacies in the nutritional composition of the menu offered to the students both in the amount of energy, as in the amounts of macro and micronutrients. The inadequacies of the values found in the nutritional composition of the school menu are harmful and expose students to nutritional deficiencies, in addition to influencing the physical, intellectual and mental development of students.
\end{abstract}

Keywords: School feeding, Menu planning, Deficiency diseases.

Resumen: Esta investigación tuvo como objetivo realizar el análisis del menú escolar brindado a estudiantes de educación básica en las redes municipales y estatales de un municipio del interior de Amazonas, comparando los datos encontrados con las recomendaciones descritas en el Programa Nacional de Alimentación Escolar (PNAE). Los datos se obtuvieron a través de la recolección de información de los menús, las hojas de preparación y las porciones de las comidas servidas en octubre de 2019 en las

\footnotetext{
${ }^{1}$ Universidade Federal do Amazonas, Instituto de Saúde e Biotecnologia (ISB/UFAM), Coari-Amazonas.

*E-mail: rainaraoliveeira06@gmail.com
} 
escuelas primarias de la red de educación Municipal y Estatal de un municipio de Amazonas. Durante el análisis de los datos se encontró una gran prevalencia de deficiencias en la composición nutricional del menú ofrecido a los estudiantes tanto en la cantidad de energía, como en las cantidades de macro y micronutrientes. Las deficiencias de los valores que se encuentran en la composición nutricional del menú escolar son perjudiciales y exponen a los estudiantes a deficiencias nutricionales, además de influir en el desarrollo físico, intelectual y mental de los estudiantes.

Palabras clave: Alimentación escolar, Planificación de menús, Deficiencias nutricionales.

\section{INTRODUÇÃO}

A inclusão da alimentação como direito humano possibilita a ampliação da promoção da alimentação adequada e saudável em diferentes âmbitos. O planejamento do consumo de alimentos em quantidades, qualidade, harmonia e adequação ideais para suprir as necessidades fisiológicas dos indivíduos tornar-se de suma importância para a manutenção do equilíbrio nutricional no organismo, uma vez que a ingestão de alimentos com baixo valor nutricional acarreta em malefícios para a saúde (BUSCHINI J, 2016).

A falta de conhecimento e a necessidade da promoção da educação nutricional em diferentes faixas etárias e classes sociais colaboram com o aumento da procura por alimentos pouco nutritivos, favorecendo a má nutrição, os erros alimentares e a baixa utilização e consumo integral dos alimentos. $\mathrm{O}$ acesso a alimentação saudável tornou-se um verdadeiro desafio e vai além da promoção da saúde, engloba também o combate à fome e a redução dos índices de desnutrição e subnutrição prevalente em crianças de famílias de baixa renda (FRANÇA CJ e CARVALHO VCHS, 2017).

Visando promover e garantir a segurança alimentar e nutricional da população brasileira e a questão da alimentação adequada como um direito fundamental reconhecido internacionalmente, no ano de 1955 foi implantado o Programa Nacional de Alimentação Escolar (PNAE) que consiste, entre outras coisas, ofertar gratuitamente alimentos nas escolas públicas durante o período letivo. As escolas no requisito de alimentação devem fornecer cardápios que são baseadas nas necessidades energética e nutricionais que cada público precisa e para o tal, pode-se utilizar o PNAE como base. Entretanto, na execução do PNAE podem existir falhas nos cardápios escolares ofertados aos alunos, favorecendo a exposição das crianças a uma alimentação pobre em nutrientes ou rica com excesso de calorias vazias sem benefícios nutricionais ao organismo (STEIL WF e POLL FA, 2017).

O objetivo deste estudo foi realizar a análise da composição nutricional do cardápio escolar da educação básica fornecida aos discentes durante um mês do ano de 2019 do ensino fundamental da rede Municipal e Estadual de Ensino em um município do Amazonas comparando os dados coletados com as recomendações do PNAE. A realização deste estudo visa colaborar de forma benéfica na ampliação de conhecimento na área de nutrição e mostrando sobre a realidade dos cardápios ofertados aos escolares da rede pública de ensino.

\section{MÉTODOS}

Este estudo é do tipo descritivo de abordagem qualitativa sobre a análise do cardápio escolar da educação básica fornecida aos discentes do ensino fundamental em um município do Amazonas. Os dados coletados foram referentes ao cardápio escolar do mês de outubro de 2019 ofertados aos alunos com faixa etária de 6 a 10 anos de idade que estudavam na Rede Municipal e na Rede Estadual do ensino fundamental I. Por se tratar de dados secundários, não foi necessário submeter o estudo ao Conselho de Ética.

No entanto, para a aquisição dos dados foi formalizado através de ofício destinado para Coordenadora Regional de Educação da Secretaria de Estado de Educação e Qualidade do Ensino (SEDUC) e para a Presidente do Conselho de Alimentação Escolar do Município (CAE) oriundo da Secretaria Municipal de Educação e Cultura a solicitação de cópias do cardápio, fichas técnicas das preparações e descrições das porções utilizadas na alimentação escolar. 
Cada cardápio foi composto por 20 preparações planejadas para 20 dias letivos para os discentes da rede pública que participam do PNAE e foram analisados os seguintes itens: energia, carboidratos, proteínas, lipídios, vitamina $\mathrm{A}$, vitamina $\mathrm{C}$, fibras alimentares, cálcio, magnésio e zinco dos alimentos. Os valores advindos dos cardápios coletados foram comparados com as recomendações do Programa Nacional de Alimentação Escolar (PNAE). Como material de auxílio deste estudo foram utilizados a Tabela Brasileira de Composição de Alimentos e o software Excel 2016 do Microsoft Office Professional Plus. Durante a análise dos dados foram feitos o desvio padrão e a média da composição nutricional ofertada por semana, sendo divididos o mês de outubro em 4 semana. Foi estipulado a tolerância de $\pm 10 \%$ entre o valor dos nutrientes e energia ofertados com o que é preconizado pelo PNAE para serem considerados adequados (TACO, 2011; BRASIL, 2013).

\section{RESULTADO E DISCUSSÃO}

Tabela 1 em relação à energia ofertada, o cardápio da rede estadual foi a mais preocupante, pois forneceu uma quantidade muito abaixo durante todo o mês de outubro de 2019. Para muitas crianças de famílias carentes, a merenda escolar acaba se tornando uma das principais, e muitas vezes, as únicas refeições realizada durante o dia, tendo em vista as baixas condições financeiras em que a família é exposta e ao acesso precário de aquisição de alimentos no local, sendo assim a ingestão baixa de energia, como visto na rede estadual, pode prejudicar a transição da fase da infância para a adolescência, pois expõe as crianças a carências nutricionais, influenciando no crescimento e desenvolvimento da criança (BUSATO MA, et al., 2015; LEROUX IN, et al., 2019).

Tabela 1 - Valores diários (média \pm desvio padrão) da composição nutricional ofertados no cardápio do mês de outubro da Rede Municipal (M) e da Rede Estadual de Ensino (E) em comparação com as recomendações do Programa Nacional de Alimentação Escolar PNAE.

\begin{tabular}{|c|c|c|c|c|c|c|c|c|c|}
\hline \multirow[t]{2}{*}{ Dados } & \multicolumn{2}{|c|}{ Semana 1} & \multicolumn{2}{|c|}{ Semana 2} & \multicolumn{2}{|c|}{ Semana 3} & \multicolumn{2}{|c|}{ Semana 4} & \multirow[t]{2}{*}{ PNAE } \\
\hline & M & $E$ & M & $\mathbf{E}$ & M & $E$ & M & $E$ & \\
\hline Energia (kcal) & $\begin{array}{l}286,8 \pm \\
42,4\end{array}$ & $\begin{array}{c}180,9 \pm \\
50,7\end{array}$ & $\begin{array}{c}364,3 \pm \\
85,4\end{array}$ & $\begin{array}{c}192,3 \pm \\
49,0\end{array}$ & $\begin{array}{c}320,6 \pm \\
93,1\end{array}$ & $\begin{array}{l}143,2 \pm \\
19,0\end{array}$ & $\begin{array}{l}298,2 \pm \\
100\end{array}$ & $\begin{array}{c}157,7 \pm \\
51,3\end{array}$ & 300,0 \\
\hline Carboidratos (g) & $\begin{array}{c}55,0 \pm \\
30,0 \\
\end{array}$ & $\begin{array}{c}31,0 \pm \\
13,0 \\
\end{array}$ & $\begin{array}{c}51,6 \pm \\
17,8 \\
\end{array}$ & $\begin{array}{c}25,8 \pm \\
10,4 \\
\end{array}$ & $\begin{array}{c}41,1 \pm \\
18,9 \\
\end{array}$ & $20,9 \pm 9,0$ & $\begin{array}{c}96,4 \pm \\
24,8 \\
\end{array}$ & $\begin{array}{c}23,5 \pm \\
12,8 \\
\end{array}$ & 48,8 \\
\hline Proteínas (g) & $\begin{array}{c}17,1 \pm \\
6,7\end{array}$ & $5,0 \pm 3,2$ & $18,2 \pm 6,1$ & $9,3 \pm 4,2$ & $21,6 \pm 4,7$ & $4,2 \pm 2,8$ & $15,9 \pm 3,9$ & $5,9 \pm 4,6$ & 9,4 \\
\hline Lipídios (g) & $6,9 \pm 3,5$ & $4,0 \pm 1,0$ & $11,2 \pm 4,8$ & $5,7 \pm 1,4$ & $8,9 \pm 2,2$ & $4,6 \pm 1,9$ & $9,9 \pm 3,6$ & $4,4 \pm 1,9$ & 7,5 \\
\hline $\begin{array}{c}\text { Fibras } \\
\text { alimentares }(\mathrm{g}) \\
\end{array}$ & $2,9 \pm 1,1$ & $1,9 \pm 1,1$ & $1,6 \pm 0,1$ & $1,8 \pm 1,1$ & $2,2 \pm 0,7$ & $0,9 \pm 0,6$ & $2,3 \pm 2,5$ & $1,7 \pm 1,0$ & 5,4 \\
\hline Vitamina A $(\mu \mathrm{g})$ & $\begin{array}{l}47,8 \pm \\
92,4\end{array}$ & $\begin{array}{c}57,7 \pm \\
22,4\end{array}$ & $\begin{array}{c}65,2 \pm \\
52,6\end{array}$ & $\begin{array}{l}45,6 \pm \\
30,6\end{array}$ & $\begin{array}{c}23,4 \pm \\
44,8\end{array}$ & $\begin{array}{c}104,0 \pm \\
15,1\end{array}$ & $\begin{array}{c}43,5 \pm \\
52,8\end{array}$ & $\begin{array}{c}78,8 \pm \\
58,4\end{array}$ & 100,0 \\
\hline Vitamina C (mg) & $\begin{array}{c}17,5 \pm \\
23,8\end{array}$ & $\begin{array}{c}35,8 \pm \\
33,5\end{array}$ & $\begin{array}{c}66,5 \pm \\
17,6\end{array}$ & $3,7 \pm 1,7$ & $13,3 \pm 9,9$ & $\begin{array}{c}18,6 \pm \\
26,1\end{array}$ & $3,5 \pm 5,3$ & $\begin{array}{c}25,1 \pm \\
24,2\end{array}$ & 7,0 \\
\hline Cálcio (mg) & $\begin{array}{l}83,0 \pm \\
130,2\end{array}$ & $\begin{array}{c}49,3 \pm \\
58,1\end{array}$ & $\begin{array}{c}171,6 \pm \\
11,1\end{array}$ & $\begin{array}{c}72,8 \pm \\
72,3\end{array}$ & $\begin{array}{c}77,4 \pm \\
99,1\end{array}$ & $\begin{array}{c}69,8 \pm \\
68,8\end{array}$ & $\begin{array}{c}119,5 \pm \\
26,9\end{array}$ & $\begin{array}{c}41,9 \pm \\
50,6\end{array}$ & 210,0 \\
\hline Ferro (mg) & $1,8 \pm 0,9$ & $0,8 \pm 0,4$ & $1,3 \pm 0,8$ & $1,7 \pm 1,1$ & $1,7 \pm 0,6$ & $1,4 \pm 1,1$ & $1,3 \pm 0,6$ & $1,3 \pm 1,2$ & 1,8 \\
\hline Magnésio (mg) & $\begin{array}{c}40,5 \pm \\
22,4\end{array}$ & $24,7 \pm 7,2$ & $34,6 \pm 8,1$ & $20,6 \pm 6,1$ & $32,3 \pm 9,9$ & $13,8 \pm 5,8$ & $29,9 \pm 7,5$ & $14,1 \pm 7,6$ & 37,0 \\
\hline Zinco (mg) & $\begin{array}{c}12,2 \pm \\
18,5\end{array}$ & $0,8 \pm 0,7$ & $2,9 \pm 2,2$ & $1,7 \pm 0,7$ & $3,8 \pm 1,6$ & $0,8 \pm 0,7$ & $2,9 \pm 1,8$ & $1,1 \pm 1,0$ & 1,3 \\
\hline
\end{tabular}

Fonte: Oliveira RS, et al., 2020.

A análise de carboidratos mostrou que o cardápio da rede estadual estava inadequado nas quatro semanas e a rede municipal mostrou estar inadequado na maioria das semanas analisadas. A ingestão inadequada de carboidrato deve ser corrigida no planejamento do cardápio escolar, pois o carboidrato é um macronutriente que atua no fornecimento de energia, proteção contra corpos cetônicos, preservação das proteínas e combustível para o sistema nervoso e sua baixa ingestão causa prejuízos ao metabolismo (BEZ A, 2017). 
Em relação a proteínas, o cardápio da rede estadual se destacou por fornecer uma quantidade menor que a preconizada na maioria das semanas analisadas. Em contraste com o cardápio da rede municipal, que mostrou também estar inaceitável, mas com valores acima do recomendado. O corpo humano é formado por proteína e sua função é primordial no metabolismo, ajuda na regeneração tecidual, reprodução e crescimento, além de atuar no transporte de nutrientes, na catalisação de enzimas e formação dos hormônios, sendo, portanto, ideal a adequação de proteínas na oferta do cardápio aos escolares sua deficiência na alimentação favorece a depleção proteica e a evolução da desnutrição (COSTA CN, et al., 2017).

$\mathrm{Na}$ análise de lipídios, foi verificado mais uma vez que na rede estadual, a quantidade fornecida estava abaixo do recomendado, já na rede municipal, na maioria do mês de outubro a quantidade de lipídios foi maior que o recomendado. A adequação de lipídios na oferta do cardápio escolar é essencial principalmente pelo fato de favorecer o transporte de nutrientes no organismo e ajudar na absorção das vitaminas lipossolúveis, além de atuam de forma benéfica executando atividades por ser um precursor de hormônio e ter a capacidade de fornecer energia, melhorar o sabor e a textura dos alimentos no paladar do comensal, entretanto, o excesso de lipídios eleva o valor energético e pode causar prejuízos ao organismo e possivelmente ajudar no desenvolvimento de doenças crônicas não transmissíveis (SOUZA AA e CADETE MM, 2017).

Em relação a quantidade de fibras alimentares, ambos os cardápios forneceram uma quantidade menor que o preconizado durante todo o mês de outubro de 2019. No estudo de Bez A (2017), também foi encontrado a oferta de fibras abaixo do recomendado aos escolares. As fibras devem ser incluídas e planejada na alimentação de maneira adequada, valorizando seus benefícios no organismo, sendo, portanto, benéfica nas suas funções vitais, tendo em vista que elas executam papéis de suma importância no metabolismo dentre eles a fibra ajudar a reduzir a absorção de gordura, promover a regularização do transito intestinal, além de fornecer saciedade e reduzir os níveis de colesterol no organismo. A busca por alimentos ricos em fibras torna-se um desafio e deve ser levado em consideração a aceitabilidade e o agrado ao paladar do comensal principalmente quando se trata do planejamento de cardápio destinado aos escolares (COSTA CN, et al., 2017).

A quantidade de vitamina $A$ fornecida na rede municipal estava abaixo do recomendado durante todo $o$ mês, enquanto que na rede estadual somente em uma semana os valores ofertados estavam de acordo com o PNAE. A deficiência de vitamina A, além de reduzir a mobilização do ferro no metabolismo, é também considerado um problema de saúde pública que vem afetando principalmente as crianças de baixa renda. $A$ vitamina $A$ é um micronutriente importantíssimo para o organismo que participa da regulação e modulação da diferenciação e crescimento celular, atualmente sua atuação fisiológica mais conhecida é na atuação do processo visual, na síntese das glicoproteínas e na iniciação do impulso nervoso (LEROUX IN, et al., 2019).

Em relação a vitamina $C$, ambos os cardápios estavam inadequados durante todo o mês, entretanto o mais preocupante foi na escola estadual na semana 2 e na semana 4 na rede estadual, por se encontrarem abaixo do recomendado. A ingestão adequada de vitamina $C$ no cardápio dos escolares é necessária para ajudar no fortalecimento do sistema imunológico, além de ser considerado um antioxidante essencial que atua na linha de defesa do organismo e possui a capacidade de combater a proliferação dos radicais livres. O planejamento adequado de cardápios promove a alimentação adequada e saudável no cotidiano dos alunos e o incentivo do consumo de alimentos de origem vegetal na forma in natura aumenta a disponibilidade de vitamina C no cardápio dos escolares (SILVA EO, et al., 2018).

Nos cardápios $\mathrm{E}$ e $\mathrm{M}$ as médias de cálcio estavam inadequadas em todas as quatro semanas estudadas e os valores encontrados apresentavam médias muito abaixo do recomendado na maioria das semanas. $O$ quantitativo de cálcio ofertado na alimentação escolar é fundamental para o desenvolvimento ósseo durante a fase da infância além de executar funções essenciais no metabolismo humano, dentre elas destaca-se a função de colaboração na realização da atividade de contração muscular e na regulação da transmissão nervosa (PIASETZKI C e BOFF E, 2018; LOPES FM e DAVI TN, 2016). No estudo realizado por Silva J, et al. (2016) com crianças de 7 a 10 anos da cidade de Colinas (SP) foi observado que houve resultados 
positivos sobre a frequência do consumo de alimentos fontes de cálcio por parte da população estudada, porém nem sempre esses alimentos consumidos possuem uma boa qualidade nutricional, devido à presença elevada de alimentos ricos em gorduras e açúcares.

Em relação ao ferro, o cardápio da rede estadual forneceu quantidades abaixo do recomendado na maioria das semanas e a rede municipal somente na metade do mês. A deficiência de ferro ainda é o principal fator que resulta nos altos índices de anemia ferropriva principalmente durante a fase da infância, na qual há uma necessidade maior de ferro sendo utilizada para a homeostase do metabolismo deste público, sendo bastante prevalente a deficiência deste nutriente em crianças de baixa renda que atualmente são bastante afetados devidos ao baixo consumo de carne e vegetais ricos em ferro durante a alimentação rotineira (SHUBHAM K, et al., 2020; MELO KM, et al., 2017; CORRÊA R, et al., 2017).

A análise de magnésio mostrou que, mais uma vez, a rede estadual forneceu uma quantidade de nutriente menor que o recomendado durante todo o mês. A rede municipal não foi muito melhor, uma vez que forneceu quantidades adequadas somente na metade do mês. No entanto, a ingestão inadequada deste mineral pode ser corrigida através da inclusão e incentivo de vegetais folhosos verdes, legumes e grão integrais na alimentação, pois são os alimentos com mais presença de magnésio na sua composição nutricional. O magnésio é um mineral absorvido no colón e no íleo, na qual executa funções fundamentais no organismo como na modulação dos sinais de transdução, no metabolismo de energia e proliferação celular, além de participar do transporte de cálcio e potássio no metabolismo (VESTENA RF, et al., 2018; VEGA JB, et al., 2015).

A análise do zinco mostrou que no cardápio da rede municipal a quantidade ofertava foi menor que 0 recomendado durante todo o mês, resultado semelhante ao cardápio da rede estadual que mostrou conter quantidades menores em três semanas. $O$ zinco atua colaborando na participação e formação de diversas proteínas que ajudam na replicação do DNA e sua deficiência é um dos fatores que caracterizam o hipogonadismo e a baixa estatura, sendo, portanto, essencial para a homeostase do metabolismo.

A presença adequada de zinco na alimentação dos escolares favorece a qualidade nutricional da alimentação, pois este nutriente executa funções catalítica, estrutural e regulatória de proteínas e enzimas, além de atuar no sistema de defesa imunológica do organismo. Para o desenvolvimento e o crescimento adequado das crianças é preciso a prática da ingestão adequada de nutrientes suficientes na alimentação, seja ela uma alimentação rotineira do lar ou em âmbito escolar, visando sempre o suprimento das necessidades metabólicas do discente, entretanto, não foi encontrado em nenhuma semana a adequação de todos os nutrientes, o que pode trazer malefícios para saúde e desenvolvimento, tanto a curto, quanto a longo prazo (CESAR JT, et al., 2018; PAES ARC, et al., 2016)

Durante a análise da composição nutricional foi observado que nos cardápios havia preparações com inclusão de alguns alimentos regionais como banana, jerimum, farinha de tapioca granulada, açaí e filé de pirarucu. No entanto o que chamou mais atenção durante a análise dos dados no cardápio foram as frequentes presenças de alimentos processados e ultra processados nas preparações planejadas aos escolares. A ingesta precoce de alimentos industrializados em conservas, no organismo atua como um verdadeiro vilão, além de favorecer o aumento dos índices de doenças crônicas e não crônicas prevalentes na população, deixando a saúde cada vez mais afetada e debilitada devido à exposição do consumo frequente de alimentos ultra processados na rotina do comensal.

A inserção de alimentos in natura ou minimamente processados na alimentação escolar é fundamental para o incentivo da alimentação adequada e saudável, através da participação da agricultura familiar em conexão com o Programa de Alimentação Escolar a inclusão de alimentos in natura ou minimamente processados deve ser promovida durante as preparações culinárias da merenda escolar, haja em vista que a transação alimentar ocorre de forma gradual na fase da infância e deve ser feita de maneira correta, pois a troca de alimentos in natura ou minimamente processados por produtos alimentícios industrializados é um ato impercebível e incorreto que tem influência direta sobre a má alimentação e acaba se tornando um dos principais fatores das carências nutricionais. A inadequação dos valores encontrados na composição nutricional do cardápio escolar é prejudicial e expõe o aluno as carências nutricionais, além de influenciar no 
desenvolvimento físico, intelectual e mental dos estudantes. A ingesta inadequada de nutrientes deve ser corrigida no planejamento do cardápio, pois a oferta de uma alimentação de qualidade promove o direito à alimentação adequada e saudável no ambiente escolar, além de incentivar o consumo de frutas, legumes e hortaliça (SOUZA AA, et al., 2017).

\section{CONCLUSÃO}

Baseado neste estudo foi observado uma grande prevalência de inadequações na composição do cardápio ofertado aos escolares, contudo, há uma prevalência maior de inadequações no cardápio da Rede Estadual de ensino. Foi observado ainda frequentes presenças de alimentos processados e ultra processados nas preparações da merenda escolar planejadas aos discentes e a ingesta precoce desses tipos de alimentos no organismo atua como um verdadeiro vilão, deixando a saúde cada vez mais debilitada. A contribuição deste estudo é de essencial importância para área da nutrição principalmente sobre a questão da aplicação correta das Recomendações do Programa Nacional de Alimentação escolar e a promoção da alimentação adequada e saudável no âmbito educacional.

\section{REFERÊNCIAS}

1. BEZ A. Aceitação da alimentação e análise do cardápio escolar de uma Escola Municipal De Francisco Beltrão-PR. Revista da Associação Brasileira De Nutrição, 2017; 8(2): 12-19.

2. BRASIL. 2013. In: Resolução CD/FNDE nํ26, de 17 de junho de 2013. Brasília: Ministério da Educação. Disponível em: https: //www.fnde.gov.br/index.php/acesso-a-informacao/institucional/legislacao/item/4620resolução-cd-fnde-no-26-de-17-de-junho-de-2013. Acesso em: 8 de out. 2019.

3. BUSATO MA, et al. Ambiente e alimentação saudável: percepções e práticas de estudantes universitários. Revista Semina: Ciências Biológicas e da Saúde, 2015; 36(2): 75-84.

4. BUSCHINI J. La alimentación como problema científico y objeto de políticas públicas en la Argentina: Pedro Escudero y el Instituto Nacional de la Nutrición, 1928-1946. Revista Ciências da Sociedade, 2016; 43(79): 129-156.

5. CARVALHO CA, et al. Consumo alimentar e adequação nutricional em crianças brasileiras: revisão sistemática. Revista Paulista de Pediatria, 2015; 33(2): 211-221.

6. CESAR JT, et al. Alimentação Escolar no Brasil e Estados Unidos: uma revisão integrativa. Revista Ciência \& Saúde Coletiva, 2018; 23(3): 991-1007.

7. CORRÊA RS, et al. Padrões alimentares de escolares: existem diferença entre crianças e adolescentes. Revista Ciência \& Saúde Coletiva, 2017; 22(2): 553-562.

8. COSTA CN, et al. Disponibilidade de alimentos na alimentação escolar de estudantes do ensino fundamental no âmbito do PNAE, na cidade de Codó, Maranhão. Caderno de Saúde Coletiva, 2017; 25(3): 348-354.

9. FRANÇA CJ, CARVALHO VCHS. Estratégias de educação alimentar e nutricional na Atenção Primária à Saúde: uma revisão de literatura. Revista Saúde em Debate, 2017; 41(114): 932-948.

10. LEROUX IN, et al. Brazilian preschool children attending day care centers show na inadequate micronutrient intake through 24 - h duplicate diet. Journal of Trace Elements in Medicine and Biology, 2019; 54: 175-182.

11. LOPES FM, DAVI TN. Inclusão de hábitos alimentares saudáveis na educação infantil com alunos de 4 e 5 anos. Cadernos da Fundação Carmelitana Mário Palmério, 2016; 15(24): 105-126.

12. MELO KM, et al. Influência do comportamento dos pais durante a refeição e no excesso de peso na infância. Escola Anna Nery, 2017; 21(4): e20170102.

13. TACO. 2011. In: Tabela brasileira de composição de alimentos (TACO). Disponível em: https://www.cfn.org.br/wp content/uploads/2017/03/taco_4_edicao_ampliada_e_revisada.pdf. Acesso em: 14 dez. 2019

14. PAES ARC, et al. Revisão bibliográfica do PNAE no contexto nutricional e educacional. Revista de Empreendedorismo e Gestão de Micro e Pequenas Empresas, 2016; 1(5): 16.

15. PIASETZKI C, BOFF E. Educação alimentar e nutricional e a formação de hábitos alimentares na infância. Revista Contexto \& Educação, 2018; 33(106): 318-338.

16. SHUBHAM K, et al. Iron deficiency anemia: A comprehensive review on iron absorption, bioavailability and emerging food fortification approaches. Trends in Food Science \& Technology, 2020; 99: 58-75. 
17. SILVA EO, et al. Alimentação escolar e constituição de identidades dos escolares: da merenda para pobres ao direito à alimentação. Caderno de Saúde Pública, 2018; 34(4): e00142617.

18. SILVA J, et al. Avaliação da frequência do consumo do cálcio na alimentação de crianças do município de Colina (SP). Revista Fafibe, 2016; 9(1): 16-27.

19. SOUZA AA, CADETE MM. O papel das famílias e da escola na formação de hábitos alimentares saudáveis de crianças escolares. Revista Pedagógica, 2017; 19(40): 136-154.

20. STEIL WF, POLL FA. Estado nutricional, práticas e conhecimentos alimentares de escolares. Revista Cinergis, 2017; 18(3): 226-232.

21. VEGA JB, et al. Fatores associados ao consumo de bebidas açucaradas entre pré-escolares brasileiros: inquérito nacional de 2006. Revista Ciências \& Saúde Coletiva, 2015; 20(8): 2.371-2.380.

22. VESTENA RF, et al. Alimentação saudável: contribuições de uma sequência didática interativa para o ensino de ciências nos anos iniciais. Revista Contexto \& Educação, 2018; 33(104): 365-394. 